\title{
COMPONENTES DEFINIDORES DO CONCEITO DE TERRITÓRIO: \\ A MULTIESCALARIDADE, A MULTIDIMENSIONALIDADE E A RELAÇÃO ESPAÇO- PODER
}

\author{
AGRIPINO SOUZA COELHO NETO \\ Universidade do Estado da Bahia
}

\section{Introdução}

A ciência geográfica construiu um acúmulo de reflexão sobre o conceito de território e suas derivações (territorialidade, des-reterritorialização). Embora a discussão sobre o conceito nunca tenha sido prisioneira das fronteiras disciplinares da geografia, como testemunha o conteúdo da obra de Haesbaert (2004), é inegável que o esforço empreendido por uma gama de geógrafos, apoiados por distintas perspectivas teórico-metodológicas, tem concorrido para o alargamento e para a problematização do debate resultando no levantamento de renovadas questões e na oferta de elementos conceituais que contribuem para a tarefa precípua desse campo disciplinar, ou seja, a compreensão da dimensão espacial da sociedade, miradas, neste caso, pelo prisma da relação espaçopoder.

No amplo leque de discussões que animam o debate geográfico (não apenas, mas, especialmente), alguns aspectos sobressaem e indicam os rumos das reflexões: a ênfase na (i) multiescalaridade e na (ii)

Haesbaert (2004) realizou um amplo levantamento das concepções de território nas ciências humanas (antropologia, ciência política, sociologia, psicologia, economia), mas, também, na filosofia e na etologia. 
multidimensionalidade da concepção de território e na centralidade da (ii) relação espaço-poder para pensar a territorialidade humana.

Esses aspectos, obviamente, não refletem a totalidade do debate geográfico, mas, sua escolha se justifica pela posição privilegiada que ocupam no âmbito das reflexões teóricas que se propuseram a (re)pensar o conceito de território, oferecendo elementos relevantes para tarefa de conceituação e definição de parâmetros operacionais para as pesquisas que se debruçam sobre a compreensão das manifestações da territorialidade. É no rastreamento do percurso e no aclaramento e na organização dessas discussões que se encontra estruturado este texto, cumprindo, também, o papel de guia das próximas seções ${ }^{2}$.

\section{A multiescalaridade do território}

A despeito da existência de controvérsias etimológicas acerca da origem e da evolução da palavra território, Haesbaert (2004) destacou dois sentidos largamente difundidos (inclusive academicamente) que são tributários do latim: o primeiro, predominante, referido à terra, tomando o território como materialidade; e o segundo, menos frequente, relacionado aos sentimentos que o território provoca, ou seja, "(...) medo para quem dele é excluído, de satisfação para aqueles que dele usufruem ou com o qual se identificam" (p. 44).

Considerando as definições que figuram em alguns dicionários de línguas vernáculas de grande circulação ${ }^{3}$, verifica-se, com determinada

2 O propósito do texto não é realizar uma varredura completa das contribuições geográficas, mas, buscou-se dialogar com alguns autores cujas ideias destacam os componentes nucleares focalizados: a multiescalaridade, a multidimensionalidade e a relação espaço-poder.

3 O Dictionnaire de la Langue Française Littré [de 1971] define o território como "a extensão de terra que depende de um império, de uma província, de uma cidade, de uma jurisdição“ (DI MÉO, 1998, p. 42, tradução nossa). O Le Petit Robert de la Langue Française (1996-1997) define como a "extensão de um país sobre o qual se exerce uma autoridade, uma jurisdição". O Novo Dicionário Aurélio da Língua Portuguesa (2004) define como a "base geográfica do Estado, sobre a qual ele exerce a sua soberania, e que abrange o solo, rios, lagos, mares interiores, águas adjacentes, 
predominância e quase que de forma homogênea, uma acepção de território como área, superfície ou extensão de terra, controlada por uma jurisdição político-administrativa, base geográfica da soberania de um Estado. Desta definição, é possível deduzir alguns elementos a fim de pensar o território como conceito, como a presença de um poder que o marca (mesmo que ainda reduzido ao poder estatal) e os limites bem demarcados, pressupondo a existência de uma exclusividade de uso (dos recursos) que se configura pelo controle e pela soberania nacional.

Talvez em decorrência da tradição jurídico-romana que o seu significado etimológico evoca, ou mesmo por seu emprego original nos estudos etológicos (sobre a territorialidade animal) e na Geografia Política, o conceito de território sugere pensar nos limites/fronteiras que o delimitam. Esse exercício torna-se mais fácil quando tomado em sua forma material clássica de manifestação, definido nos domínios políticos do Estado. Segundo Souza (1995), a concepção de território na tradicional Geografia Política, fixado na escala nacional e assentado na figura do Estado-nação, pressupunha limites espaciais e temporais com pequena mobilidade, pois, entende a durabilidade como geradora de raízes e identidade sociocultural. As durabilidades das fronteiras nacionais permitiram a construção da ideia de fixidez dos territórios, naturalizando as fronteiras estatais (SOUZA, 2009).

A compreensão do território como um espaço com limites estabelecidos por fronteiras coloca, por conseguinte, a questão da exclusividade de apropriação e de uso, distinguindo "nós" (os incluídos, aqueles que integram o território) e os "outros" (aqueles que não fazem parte do território). Nessa perspectiva, enquadra-se adequadamente o recorte do Estado territorial, com limites estabelecidos de apropriação, uso, gestão e controle de fração do espaço, como um domínio político-estatal, cujo acesso exige a permissão de uma autoridade, de um poder instituído concentrado na figura do Estado.

O pressuposto da existência de fronteiras bem delimitadas e definidoras dos membros da coletividade territorial, como conteúdo do conceito de território, não foi uma exclusividade da clássica Geografia

golfos, baías e portos”. Definição análoga a esta última aparece no Dicionário Houaiss da Língua Portuguesa (2007). 
Política, mas compareceu em outras formulações de geógrafos, conforme a definição de Soja (1971), considerando a territorialidade como

um fenômeno de comportamento associado à organização do espaço em esferas de influência ou em territórios nitidamente delimitados, que assumem características distintas e podem ser considerados, pelos menos em parte, como exclusivos de quem os ocupa e de quem os define (SOJA, apud ROCANYOLO, 1988, p. 263, grifos nossos).

As condições que constroem a distinção entre os membros de uma coletividade territorial e os outros, que a ela não pertencem, aparecem também em Raffestin (1988, p. 265, tradução nossa), ao definir a territorialidade humana como o "(...) conjunto de relações mantidas pelo homem, enquanto pertencentes a uma sociedade [coletividade, segundo Raffestin, 1986], com a exterioridade e a alteridade com a ajuda de mediadores ou instrumentos (...)". Portanto, "falar de território é fazer uma referência implícita à noção de limite (...)" que pode ser expressa pela “(...) relação que um grupo mantém com uma porção do espaço", gerando uma delimitação, que, por sua vez, significa "manifestar um poder numa área precisa" (RAFFESTIN, 1993 [1980], p. 153). Contudo, o autor adverte que delimitar (marcar, cercar - arremata o autor) parcelas não é uma simples relação com o território, pressupondo uma relação triangular, pois, "a relação com o território é uma relação que mediatiza em seguida as relações com os homens, com os outros" (p. 160). Essa perspectiva aponta inequivocamente para as relações de poder que são constitutivas da territorialidade e que ocuparam posição privilegiada no pensamento do autor (discussão que realizaremos adiante).

A delimitação de fronteiras e o controle do acesso aos recursos são características fundamentais da concepção de territorialidade de Sack (1986), como no exemplo usado pelo autor, tomando uma região de produção agrícola ou manufatureira, que se torna território quando designada pelo governo para receber um investimento público ou quando delimitada para ser administrada por um órgão governamental. Desse modo, as fronteiras delimitam uma jurisdição e afetam o acesso aos recursos e ao poder. Seguindo nesta direção, o autor sugere três relações interdependentes presentes na definição de territorialidade que revelam a sua lógica e os seus efeitos significativos: (i) "envolvendo uma forma de 
classificação de área"; (ii) "contendo uma forma de comunicação, por meio de um marcador ou sinal, como é comumente encontrada em uma fronteira [um limite]"; e (iii) "uma tentativa de impor o controle sobre o acesso a uma área e às coisas dentro dela, ou às coisas fora dela, contendo aqueles que estão dentro" (p. 21-22, tradução nossa).

Entretanto, mesmo considerando a centralidade das fronteiras e dos limites que lhe são atributos, tanto em Raffestin (1993 [1980]), quanto em Sack (1986), já contém a ideia que expande a possibilidade de concepção de territórios não restritivos aos recortes do Estado-nação, ampliando as escalas espaciais e temporais da territorialidade. Desse modo, "do Estado ao indivíduo, passando por todas as organizações pequenas ou grandes, encontram-se atores sintagmáticos [aqueles que realizam um programa] que 'produzem' o território", pois, "em graus diversos, em momentos diferentes e lugares variados, somos todos atores sintagmáticos que produzem "territórios"” (RAFFESTIN, 1993 [1980], p. 152).

A literatura geográfica ${ }^{4}$ atribui a Sack (1986) uma valiosa contribuição no sentido de libertar o conceito de território de sua prisão original, isto é, da referência exclusiva à dimensão do Estado nacional (mas também da carga naturalista que lhe fora imputada, tributária da abordagem etológica da territorialidade animal). $\mathrm{O}$ autor recusa a natureza imutável e fixa da territorialidade, propugnando seu caráter móvel e variável em termos de temporalidade e espacialidade, pois, “(...) um lugar pode ser um território num momento e não (ser) em outro, e um território (territorialidade) pode criar um lugar onde não existia antes. Além disso, a afirmação da territorialidade pode ser aplicada somente por um tempo limitado" (p. 16, tradução nossa).

Um aspecto destacado por Haesbaert (2004) refere-se à dimensão estratégica da territorialidade na concepção de Sack, que pode ser ativada e desativada, “(...) um recurso estratégico que pode ser mobilizado de acordo

Argumentos nessa direção podem ser encontrados em Haesbaert (2004) e Brito (2005).

5 Os exemplos arrolados pelo autor possuem grande variedade de natureza e de escala geográfica, podendo se manifestar desde a casa ou de uma prisão, até os navios de diferentes nacionalidades. 
com o grupo social e seu contexto histórico e geográfico."(HAESBAERT, 2004, p. 87). Esta acepção atinge a ideia de durabilidade que fundamentou a concepção predominante de territorialidade como algo estático e sem flexibilidade.

Souza (1995), em um texto que alcançou o mérito de problematizar o debate sobre o conceito de território na geografia brasileira, assumindo um esforço de arejamento desse conceito e buscando libertá-lo das amarras espaciais e temporais a que esteve submetido na Geografia Política Clássica, sintetiza bem a ideia de flexibilidade e mobilidade das múltiplas escalas da territorialidade:

\begin{abstract}
Territórios existem e são construídos (e desconstruídos) nas mais diversas escalas, da mais acanhada (p. ex., uma rua) à internacional (p. ex., a área formada pelo conjunto dos territórios dos países-membros da Organização do Tratado do Atlântico Norte - OTAN); territórios são construídos (e desconstruídos) dentro de escalas temporais as mais diferentes: séculos, décadas, anos, meses ou dias; territórios podem ter um caráter permanente, mas também podem ter uma existência periódica, cíclica (p. 81).
\end{abstract}

A discussão realizada nos sugere pensar no território enquanto processo da dinâmica social (e, nesse sentido, na territorialização), mas, sobretudo, na multiescalaridade da territorialidade, considerada a partir de pelo menos três elementos basilares que comparecem, implícita ou explicitamente, nos textos arrolados até aqui: a flexibilidade, a descontinuidade e a superposição são (pelo menos três) noções que compõem o conteúdo da multiescalaridade, concebidas através do movimento tempo-espaço conjugados. Desse modo:

i. Considerar a noção de flexibilidade para pensar na construção de territórios se contrapõe à ideia de limites fixos e imutáveis e das longas durabilidades das territorialidades.

ii. Trabalhar com a noção de descontinuidade confronta com a clássica concepção de territórios-zona, sustentada no pressuposto da contiguidade espacial, e pressupõe, por exemplo, considerar a ideia de território-rede. 
iii. Admitir a perspectiva da superposição de territorialidades refuta a ideia de exclusividade de uso do território, amparado na existência de fronteiras claramente bem demarcadas.

Refletindo a partir da tensão entre o fechamento e a flexibilidade das fronteiras, colocada pela complexidade dos processos migratórios contemporâneos, Haesbaert (2009) eleva a complexidade desse debate, ao analisar os processos de contenção territorial, problematizando a discussão e oferecendo um ângulo diferente de tratamento do assunto:

Se as territorialidades clássicas - inclusive a do Estado-nação, tal como foi concebido dentro do que Foucault denomina 'poder soberano' - indicavam uma distinção mais clara entre o dentro e o fora, o mesmo e o diferente, o 'nativo' e o estrangeiro, cabe destacar, finalmente, que se trata agora de uma des-ordem territorial marcada muito mais pela ambiguiidade, onde o próprio processo que construímos para 'conter' o outro, na verdade 'nos contém' e onde o 'outro' como no caso dos grandes fluxos migratórios Sul-Norte - está cada vez mais no 'nosso' território, do nosso lado (HAESBAERT, 2009, p. 118).

Além de ampliar (e polemizar) o debate sobre as fronteiras territoriais e suas implicações na dinâmica político-social contemporânea, o autor nos remete a uma noção nuclear para os propósitos de reflexão sobre o território: o poder. O próprio debate sobre as fronteiras do território suscita sua discussão, pois, como afirmou Raffestin (1993, [1980], p. 153), "delimitar é, pois, isolar ou subtrair momentaneamente ou, ainda, manifestar um poder numa área precisa". De outro modo, a centralidade da noção de poder nos parece presente no pressuposto da multiescalaridade; afinal, pensar na formação de territórios em múltiplas escalas espaciais e temporais e, não apenas, na escala unitária do Estado-nação, pressupõe outra(s) concepção(ões) de poder, que não se reduz(em) ao poder soberano do Estado, mas que possa(m) considerar sua manifestação em toda microfísica social. Portanto, são as complexas relações de poder entre os mais variados agentes que operam em múltiplas escalas que permitem pensar na multiescalaridade do território, ou seja, nas múltiplas escalas em que o poder se manifesta e se exerce. 


\section{Relação espaço-poder e território}

A condição fundante, que as relações de poder desempenham na reflexão sobre a territorialidade, é uma assertiva que goza de uma flagrante unanimidade entre os geógrafos; pelo menos, se constitui numa ideia relativamente constante entre aqueles que dispensaram seus esforços para erigir o território à condição de categoria de análise da geografia. Há pelo menos três décadas, os geógrafos têm insistido na centralidade do conceito de poder para pensar a territorialidade. A manifestação mais contundente desse pressuposto pode ser encontrada na obra "Pour une Géographie du Pouvoir", de Raffestin (1993) [publicada originalmente em 1980]. O papel que o conceito de poder ocupa em seu pensamento é inegável, ao ponto de o autor propor uma geografia do poder em oposição à tradicional geografia política, dedicando ao conceito, a tarefa de articular as temáticas políticas à geografia e conformar uma problemática. Para ele, "o território (...) é a cena do poder e o lugar de todas as relações" (p. 58).

Concebendo os territórios como formas socialmente construídas e a partir de uma perspectiva relacional, Sack (1986) vai afirmar que "as relações humanas no espaço são o resultado da influência e do poder" (p. $26)^{6}$, portanto, a "territorialidade é uma expressão geográfica primária do poder social" (p. 5) 7 , e Souza (1995) vai decretar o "território como espaço definido e delimitado por e a partir de relações de poder" (p. 96). Reafirmando essa idéia basilar (e em concordância com Raffestin), Di Méo (2001) considera que “(...) o poder tece a substância do território. Ele contribui para construir e dar-lhe forma" (p. 247) ${ }^{8}$. Haesbaert (2009), por sua vez, argumentando sobre a multidimensionalidade do território (discussão focalizada na próxima seção), oferece mais um argumento na mesma direção, conforme explicita:

O território se define mais estritamente a partir de uma abordagem sobre o espaço que prioriza ou que coloca seu foco, no interior dessa dimensão espacial, n-a 'dimensão', ou

\footnotetext{
6 "Human spatial relations are the results of influence and power" (SACK, 1986, p. 26)

7 "Territoriality is a primary geographical expression of social power" (SACK, 1986, p. 5).

8 "[...] le pouvoir tisse la substance du territoire . Il contribue à le fonder et à le façonner” (DI MÉO, 2001, p. 247).
} 
melhor, n-as problemáticas de caráter político ou que envolvem a manifestação/realização das relações de poder, em suas múltiplas esferas (HAESBAERT, 2009, p. 105).

Mas essa não é uma constatação exclusiva dos geógrafos, pois, na década de 1970, Pierre Legendre (1976, citado por Di Méo, 1998, p. 47) [francês, historiador do direito], já considerava “(...) que 'o território não é a simples divisão hierárquica, nem a repartição de competências hierárquicas', mas ele se confunde com 'uma manifestação quase epifânica do poder estendido sobre a humanidade","9

O poder é um conceito central na filosofia política e nas ciências sociais. Um grande número de pensadores se ocupou dele para pensar o fenômeno político na sociedade. Esse é um fato que contribui para a existência de uma multiplicidade de concepções que não permite a instalação de um consenso a seu respeito, situação bastante comum quando se trata de conceitos dessa envergadura. No entanto, constata-se, em muitos casos, a prevalência de abordagens excludentes, posição que desconsidera a própria temporalidade/espacialidade que carrega consigo uma visão de mundo com seus valores, intencionalidades e vivências, que contextualizam as concepções particulares. $\mathrm{O}$ desenvolvimento do pensamento humano se erige no estabelecimento do debate, na existência de discordâncias e críticas, no conflito de ideias, mas, é construído também, através de aproximações, recuperações e diálogos, enfim, do entrecruzamento de ideias. Nessa direção, encontramos o testemunho inquieto oriundo das ciências sociais que pondera sobre três dificuldades enfrentadas no tratamento do controverso conceito de poder:

De fato, qualquer um que decida se embrenhar na literatura sobre o tema encontrará três dificuldades recorrentes: primeira, a multiplicidade de definições, em geral, apresentadas como excludentes sem que o sejam de fato; segundo, os problemas de operacionalização das definições, sendo algumas delas muito precisas, mas muito superficiais, e

9 “[...] que 'le territoire n'est pas la simple division hiérarquique, ni la répartition des compétences hiérarquiques', mais qu'il se confond avec 'une manifestation quase épiphanique du povoir répandu sur l'humanité"” (LEGENDRE, 1976, citado por DI MÉO, 2001, p. 47) 
outras mais sofisticadas, porém de difícil aplicação empírica; por fim, a justaposição de definições, já que alguns utilizam palavras diferentes para designar os mesmos fenômenos ou lançam mão dos mesmos termos para designar relações sociais distintas (PERISSINOTTO, 2008, p. 29).

A constatação do longo e denso acúmulo de reflexões sobre o poder na filosofia política, cujo reflexo comporta uma multiplicidade de concepções, exige esforços sistematizadores do pensamento, como aquele empreendido por Bobbio (2007 [1985], p. 77-78), considerando a existência de três teorias fundamentais sobre o poder: (i) a teoria substancialista, perspectiva presente no pensamento de Thomas Hobbes $^{10} \mathrm{e}$ de Bertrand Russell ${ }^{11}$, concebe o poder "(...) como uma coisa que se possui e se usa como um outro bem qualquer"; (ii) a teoria subjetivista, característico da interpretação de John Locke, por sua vez, entende que o poder não é “(...) a coisa que serve para alcançar o objetivo mas a capacidade do sujeito de obter certos efeitos (...)"; e por fim, (iii) a teoria relacional, com maior aceitação no discurso político contemporâneo, considerando o poder como “(...) uma relação entre dois sujeitos, dos quais o primeiro obtém do segundo um comportamento que, caso contrário, não ocorreria". Embora Bobbio (2007 [1985], p. 78) reconheça nas ideias do cientista político norte-americano Robert Dahl "a mais conhecida e também a mais sintética das definições relacionais", não é possível defender um consenso no âmbito dessa perspectiva, tamanha a distinção que se verifica entre o referido autor (Dahl) e o pensamento de outros autores que concebem o poder, também, como um fenômeno relacional, a exemplo de Michel Foucault e Hannah Arendt (focalizados adiante). A dificuldade da classificação do pensamento se mostra arredia em outro caso, mais precisamente, quando Bobbio (2007 [1985]) enquadra em

10 Para Hobbes (2005 [1651], p. 53) "o poder de um homem, universalmente considerado, consiste nos meios de que pretensamente dispõe para obter qualquer visível bem futuro, é tanto original como instrumental".

11 Para Bertrand Russell (1979 [1938], p. 24) “o poder pode ser definido como a produção dos resultados pretendidos. É, pois, um conceito quantitativo: de dois homens com desejos semelhantes, o que realizar mais que o outro será o que tem mais poder". 
campos teóricos distintos (teorias substancialista x subjetivista), autores da filosofia política, geralmente considerados no quadro dos pensadores do contrato social, como nos casos de Hobbes e Locke, acima mencionados.

Outra perspectiva classificatória foi elaborada por Perissinotto (2008), reconhecendo dois grandes campos conceituais nas reflexões elaboradas sobre o conceito de poder. A proposta divisória do autor opõe, em um primeiro plano, duas concepções conceituais, tomadas em sua generalidade como antagônicas, distinguindo: (a) aquela que considera as relações de poder como hierárquicas, assentadas nas idéias de conflito e de predomínio, (b) daquelas que entendem o poder como um conjunto de interações voltadas para a obtenção de interesses coletivos, calcado na construção do consenso [exemplificado pelo autor como característico da interpretação de Hannah Arendt]. Em segundo plano, subdivide o primeiro campo em duas perspectivas, separando (i) a concepção de poder como "imposição da vontade", definindo-o "[...] como uma interação entre atores conscientes dos seus interesses e do caráter antagônico de suas preferências" (p. 30), tendo em Max Weber um exemplo desse tipo de formulação e (ii) e o poder como produção de um "consenso ilusório" caracterizando-se pela desconfiança em relação ao aludido consenso, entendendo-o como uma relação social “(...) que distribui desigualmente recursos sociais (econômicos, políticos, simbólicos), mas cujo funcionamento ocorre, em geral, à revelia da consciência dos atores" (p. 30), interpretações imputadas a Michel Foucault e Pierre Bourdieu, mesmo considerados em suas distinções internas. A esquematização de Perissinotto (2008) não contempla os clássicos fundadores do moderno conceito de poder, mas, opera a partir de autores de ampla aceitação e atualidade, cujas ideias têm sido objeto da apropriação mais recente pelos geógrafos, nos esforços que empreenderam para pensar a territorialidade humana, daí sua relevância para a construção deste texto.

A concepção de território, tanto na ciência política, como no direito político, esteve subsumida à discussão sobre o Estado, sendo considerado como um dos três elementos constitutivos do próprio Estado, assim como povo e soberania. Um exemplo desse tipo de vínculo aparece na definição do Jurista Italiano Constantino Mortati, citado por Bobbio (2007 [1985], p. 94), concebendo o Estado como “(...) um ordenamento jurídico destinado a exercer o poder soberano sobre um dado território, ao qual estão necessariamente subordinados os sujeitos a ele pertencentes". Assim, o 
território “(...) torna-se o limite da validade espacial do direito do Estado, no sentido de que as normas jurídicas emanadas do poder soberano valem apenas dentro de determinadas fronteiras (...)". Nesta perspectiva, segundo Bobbio (2005), o pressuposto necessário e fundamental para a existência do Estado seria a formação de um poder sobre determinado território, reunindo as condições de tomar as decisões e emanar os comandos correspondentes.

A concepção de território em Friedrich Ratzel, fortemente contestada pelo seu caráter naturalista e coisificado (SOUZA, 1995), encontra alguns pontos de tangência com a concepção jurídico-política descrita por Bobbio (2007 [1985]), sem, no entanto secundarizar sua importância (do território) para compreensão e formulação de uma teoria do Estado. A tradição geográfica reconhece em Ratzel a pioneira formulação teórica do conceito de território ${ }^{12}$, constituindo-se, segundo Costa (1992), em um clássico fundador da Geografia Política. Ratzel tem como universo de análise, as disputas territoriais entre os Estados europeus, sobretudo, pensados, a partir da particularidade histórica alemã. Desse modo, as relações entre os grupos humanos pela apropriação da superfície terrestre, ou seja, pela conformação de seus territórios, sustenta-se em processos conflituosos de conquista territorial e dominação. O território é para Ratzel (1990, p. 23) “(...) uma determinada porção da superfície terrestre apropriada por um grupo humano". Considera-o como o fundamento da existência e da potência do Estado, cujo crescimento ou decadência decorre da capacidade de gerir e expandir seu território, pois, as guerras são encaradas como "o meio mais poderoso de que dispõe um estado para perseguir seu crescimento perdido em período de paz e esclarecer as relações interestatais conflituosas" (RATZEL, apud COSTA, 1992, p. 37). Desse modo, a concepção de Raztel privilegiou “(...) um tipo de fonte de poder em particular, mas também se tornou difícil descolar o emprego da palavra das necessidades ideológicas específicas vinculadas à legitimação dessa fonte de poder" (SOUZA, 2009, p. 62): o poder que se estabelece a partir da soberania do Estado nacional.

12 Embora Souza (2009, p. 63) questione essa ideia, afirmando que não são poucos os autores que "continuaram a lidar com a herança de Ratzel como se ali já existisse um 'conceito de território', quando, a rigor, o que há são numerosíssimas alusões ao solo (Boden), ou mesmo ao Territorium em um sentido em que a especificidade latente não dá margem a uma autêntica 'emancipação' conceitual". 
Dentre os autores mais recentes (pelo menos considerando as três últimas décadas do pensamento geográfico), sobretudo, dentre aqueles que reforçam a centralidade do poder para entender a territorialidade, e que, direta ou indiretamente explicitam as concepções de poder que sustentam seus trabalhos, constata-se determinado predomínio das abordagens focalizadas na sistematização de Perissinotto (2008), especialmente nos casos das apropriações de Max Weber, Michel Foucault e Hannah Arendt, que figuram como referenciais basilares.

Adotando essa direção para nossa empreitada, é possível depreender elementos de convergência entre o conceito de territorialidade de Robert Sack (1986) e a concepção de poder de Webber (1994). Para Sack (1986), a territorialidade é "definida como a tentativa por um indivíduo ou grupo para afetar, influenciar ou controlar pessoas, fenômenos e relações, pela delimitação e afirmação do controle sobre uma área geográfica" (p. 19) ${ }^{13}$. Desse modo, a territorialidade é concebida como uma estratégia espacial para afetar, influenciar e controlar recursos e pessoas. Essa definição permite um entendimento na direção apontada por Brito (2005), ao considerá-la proveniente da concepção de poder weberiana. É possível reconhecer que as relações sociais que se derivam desse sentido de territorialidade indicam a presença das noções de domínio e controle, vinculados à ideia de imposição de vontade.

Segundo Perissinotto (2008), a perspectiva que toma o poder como "imposição de vontade" encontra inspiração no pensamento de Max Weber, considerando que, no processo de interação, os agentes sociais tentam realizar seus objetivos, acessando os recursos disponíveis para fazer prevalecer seus propósitos numa relação social. Weber (1994) define categoricamente o poder como "toda possibilidade de impor a própria vontade numa relação social, mesmo contra resistências, seja qual for o fundamento dessa probabilidade" (p. 33). Desse modo, o poder se realiza na relação social, entendida como "o comportamento reciprocamente referido a seu conteúdo de sentido por uma pluralidade de agentes e que se orienta por essa referência" (p. 16). A ideia de conflito ganha sentido na medida em que Weber pressupõe a existência de incompatibilidade de

13 “(...) defined as the attempt by an individual or group to affect, influence, or control people, phenomena, and relationships, by delimiting and asserting control over a geographic area". (SACK, 1986, p. 19). 
interesses. Já o predomínio se realiza através do desigual acesso aos recursos que possibilitam a imposição de vontade ao outro, afetando seu comportamento.

A concepção de poder de Max Weber (1864-1920) deve ser entendida no contexto da análise do sistema de dominação que o autor procurou compreender. É no âmbito do que ele denomina de "sociologia da dominação" que o focalizado conceito ganha sentido. É na análise das estruturas e funcionamento da dominação, ocupando-se centralmente dos processos de ordem burocrático-adminstrativa e das relações comerciais e trabalhistas que se realizam no domínio econômico, que o conceito de poder é acionado e desenvolvido. $\mathrm{O}$ autor atribui ao sistema de dominação um papel fundamental nas formações sociais, tratando-se de um componente indissociável do fenômeno político, uma forma especial de poder.

Claude Raffestin, outro autor de reconhecida contribuição para o debate sobre o conceito de território, ergue o poder a uma posição de centralidade em seu trabalho, localizando sua inspiração no pensamento foucaultiano, conforme declara abertamente, na obra em que erige uma teoria da geografia política (Por uma Geografia do Poder).

Para Raffestin (1993), o território “(...) é o resultado de uma ação conduzida por um ator sintagmático (ator que realiza um programa) em qualquer nível” (p. 143). Trata-se de “(...) um espaço onde se projetou um trabalho, seja energia e informação, e que, por conseqüência, revela relações marcadas pelo poder" (p. 144). Na concretização de um programa, o ator idealiza um projeto e busca assegurar "a ligação entre os objetivos intencionais e as realizações" (p. 145), processo que se desenrola através de embates no plano das relações sociais; afinal, como defende Foucault (2009 b, p. 105), “(...) não há poder que se exerça sem uma série de miras e objetivos". Em consonância com Foucault, Raffestin (1993) considera o poder como consubstancial, "parte intrínseca de toda relação" (p. 52), pois, ele [o poder] "se manifesta por ocasião da relação" (p. 53). O poder "é um processo de troca ou de comunicação quando, nas relações que se estabelecem, os dois polos fazem face um ao outro ou se confrontam" (p. 52). Assim como Foucault, Raffestin (1993) admite a existência da resistência, considerando-a como a expressão do "(...) caráter dissimétrico que quase sempre caracteriza as relações" (p. 52). O problema é que Foucault (2009 b) não entende as relações de poder como "uma oposição 
binária entre dominadores e dominados" (p. 104), mas como uma multiplicidade de correlações de forças, que "se exerce a partir de inúmeros pontos e em meio a relações desiguais e móveis" (p. 104).

Michel Foucault trabalha a partir de uma perspectiva genealógica, o que explica seu percurso na história para compreensão das formas de poder predominantes na sociedade em cada contexto espaço-tempo. É nessa direção, a partir de realidades históricas e geograficamente delimitadas, que ele reconhece a existência de modos de operação do poder. $\mathrm{O}$ caminho percorrido por Foucault (2002) tem como ponto de partida o debate da teoria clássica da soberania, que pressupõe a existência de um poder soberano que detém o direito sobre a vida e a morte dos indivíduos, identificando, desse modo, como a questão da "vida começa a se problematizar no campo do pensamento político, da análise do poder político" (p. 288). Na perspectiva jurídica contratualista, "quando os indivíduos se reúnem para constituir um soberano, para delegar a um soberano um poder absoluto sobre eles" (p. 287), o fazem em decorrência da necessidade de proteção de suas vidas. Esses princípios constituíram-se em "instrumentos da luta política e teórica em relação aos sistemas de poder dos séculos XVI e XVII" (FOUCAULT, 2007, p. 187), acionados para justificação/legitimação ou questionamento do poder das monarquias.

No entanto, a abordagem foucaultiana desloca a análise do "edifício jurídico da soberania, dos aparelhos de Estados e das ideologias que o acompanham" (FOUCAULT, 2007, p. 186), dirigindo seu foco para uma rede de poderes que perpassam toda a estrutura da sociedade, erigindo, assim, a sua microfísica do poder. Desse modo, Foucault identifica o surgimento do poder disciplinar no final do século XVII, centrado no desenvolvimento de mecanismos de vigilância e de adestramento do corpo dos indivíduos, que cria um ordenamento espacial dos homens, buscando fabricar "corpos submissos e exercitados, corpos "dóceis", além de aumentar "as forças do corpo (em termos econômicos de utilidade)", e reduzir, por outro lado, "essas mesmas forças (em termos políticos de obediência)" (FOUCAULT, 2009b, p. 133-4). No final do século XVIII, observa-se o nascimento de outra tecnologia de poder, o biopoder, que se articula com o poder disciplinar, mas que diferentemente deste,

se dirige à multiplicidade dos homens, não na medida em que se resumem em corpos, mas na medida em que ela forma, ao 
contrário, uma massa global, afetados por processo de conjunto, que são próprios da vida, que são processos como nascimento, a morte, a produção, a doença, etc. (FOUCAULT, 2002, p. 289).

Distintamente de Weber, para quem a resistência se manifesta apenas eventualmente nas relações de poder, para Foucault (2009a) "lá onde há poder há resistência", uma vez que esta última "nunca se encontra em posição de exterioridade em relação ao poder" (p. 105).

No contexto brasileiro, a concepção foucaultiana de poder tem inspirado as sistematizações mais recentes de Rogério Haesbaert, sobretudo, quando empreende o debate sobre a questão da "i-mobilidade" e da "contenção territorial" na sociedade contemporânea. Haesbaert (2009), fundamentado na ideia de que os conceitos “(...) são moldados através de problemáticas sociais geo-historicamente contextualizadas” (p. 108), parte da distinção entre a "sociedade disciplinar moderna" (prevalente nos séculos XVIII, XIX e primeira metade do século XX), voltada para o processo de reclusão, vigilância e prevenção; e a "sociedade de controle ou de segurança" (conformada desde meados do século XX), centrada na ideia de contenção e "dominada por uma forma de poder especifica, o biopoder [Foucault, 2002] - que, mais do que um poder sobre o corpo-indivíduo [foco do poder disciplinar foucaultiano], é um poder sobre a reprodução humana, a espécie-'população"” (HAESBAERT, 2009, p. 109).

$\mathrm{O}$ autor aponta o papel ambíguo desempenhado pelo atual sistema técnico-informacional, pois, num mundo que vem sendo caracterizado nas principais análises sobre a globalização pela valorização da instantaneidade, da mobilidade e da fluidez, elas (as técnicas), também, viabilizam e controlam a circulação, sobretudo, os fluxos populacionais. Desse modo, altera-se o foco das tecnologias do poder, passando “(...) da 'reclusão' dos indivíduos 'anormais' pretensamente resgatáveis (pelo menos à sociedade do trabalho) para aquilo que denominaremos a 'contenção' das massas (ou da 'população' - o homem visto, sobretudo, enquanto espécie biológica)" (HAESBAERT, 2009, p. 111). Na noção de contenção territorial deve ser considerado o "caráter sempre parcial, provisório e paliativo dos 'fechamentos', ou melhor, do efeito-barragem que cria através das tentativas de contenção dos fluxos (...)", pois, quando se obstrui um caminho, sempre aparece "outro vertedouro por onde [os fluxos] possam fluir" (p. 115). É desse modo que o autor tem pensado nos 
fenômenos dos fluxos migratórios dos países no sentido Norte/Sul e nas políticas governamentais nas favelas da cidade do Rio de Janeiro.

As ideias políticas de Hannah Arendt, mais especificamente, sua concepção de poder, têm encontrado rebatimento entre geógrafos brasileiros. Sob sua inspiração, Souza (1995) desenvolve uma interessante articulação, apoiada nas concepções do filósofo Cornelius Castoriadis, dialogando com os conceitos de território, autonomia e desenvolvimento, que resulta na construção da ideia de "territorialidade autônoma". Segundo Souza (1995), a palavra autonomia é de origem grega, significando "(...) o poder de uma coletividade se reger por si própria, por leis próprias" (p. 105). Nessa perspectiva, a construção da autonomia seria a base do desenvolvimento, "(...) encarado como o processo de autoinstituição da sociedade rumo a mais liberdade e menos desigualdade" (p. 105).

\begin{abstract}
Uma sociedade autônoma é aquela que logra defender e gerir livremente seu território, catalizador de uma identidade cultural e ao mesmo tempo continente de recursos, recursos cuja acessibilidade se dá, potencialmente, de maneira igual para todos. Uma sociedade autônoma não é uma sociedade 'sem poder', o que aliás seria impossível (...) No entanto, indubitavelmente, a plena autonomia é incompatível com a existência de um Estado enquanto instância de poder centralizadora e separada do restante da sociedade (SOUZA, 1995, p. 106).
\end{abstract}

Nessa ideia de "territorialidade autônoma" de Souza (1995), a concepção de poder assume o entendimento propositivo de Hannah Arendt, caracterizado pela possibilidade de legitimidade instituída por um grupo, pois, o poder seria uma construção coletiva, que emerge através do consenso que se realiza nas relações horizontais entre os agentes sociais.

O pensamento político de Arendt encontra motivação na oposição aos regimes totalitaristas, tendo como pano de fundo, o nazismo alemão, o fascismo italiano e o comunismo soviético. $\mathrm{Na}$ obra que elabora sua concepção de poder, dirige seu esforço para desvincular os conceitos de poder e de violência, negando que o conteúdo deste último possa ser considerado como componente intrínseco do primeiro. É nessa direção que ela se opõe às concepções que entendem a violência como a manifestação 
maior e extrema de poder, elaborando uma crítica às ideias de Max Weber, Wrigth Mills, Voltaire, Bertrand de Jouvenel e Mao Tse-tung.

Em Arendt (2009), a concepção de poder assume um caráter muito mais propositivo, caracterizado pela possibilidade de legitimidade instituída por um grupo, pois,

O poder corresponde à habilidade humana não apenas para agir, mas para agir em concerto. O poder nunca é propriedade de um indivíduo; pertence a um grupo e permanece em existência apenas enquanto o grupo se conserva unido. Quando dizemos que alguém está 'no poder', na realidade nos referimos ao fato de que ele foi empossado por um certo número de pessoas para agir em seu nome (ARENDT, 2009, p. 60-61).

Desse modo, o poder compreende uma ação coletiva, concertada, baseada no debate, mas que "preserva a pluralidade humana com sua vasta gama de interesses, opiniões e pontos de vistas distintos e mesmo conflitantes" (DUARTE, 2009, p. 143). Frente à ilegitimidade e à necessidade de justificação da violência, o poder encontra seu caráter legitimo no "apoio do povo que confere poder às instituições de um país, e esse apoio não é mais do que a continuação do consentimento que trouxe as leis à existência” (ARENDT, 2009, p, 57).

Um estudo de fôlego foi desenvolvido por Brito (2008), apoiando-se na concepção de poder de Hannah Arendt, para fundamentar seu entendimento de território. $\mathrm{O}$ autor elege o Recôncavo baiano como pano de fundo, no qual se manifesta uma territorialidade gestada através do consenso entre diversos agentes sociais, liderados pela Petrobrás. A territorialidade é concebida como:

[...] o conjunto de relações mediadas pelo poder entre os distintos agentes sociais (Estado/Governo, empresas, instituições sociais,..., cidadãos), que se interessam por algum objeto comum localizado numa dada porção do espaço geográfico. A territorialidade implica a capacidade desses agentes sociais de produzirem e/ou organizarem sistematicamente territórios, segundo um projeto orientado por um agente hegemônico (BRITO, 2008, p. 19). 
A concepção de territorialidade do autor encontra suporte na concepção de hegemonia de Antonio Gramsci e de poder de Hannah Arendt. Brito (2008) defende que o fundamento das relações de poder entre agentes em uma relação social é baseado na construção do consenso e nunca, na prevalência de submissão. No entanto, ele admite a assimetria como ingrediente das aludidas relações e pressupõe a existência de um agente hegemônico que vai conduzir o processo, exercendo uma posição de liderança.

Das ações de liderança de um agente hegemônico num dado território resulta que o conteúdo que atribui identidade aos territórios reflete mais fortemente as materializações dos interesses dos agentes hegemônicos que coordenam legitimamente o consenso formado tacitamente ou não em torno de um cronograma de objetivos, mediado pelas perspectivas desses agentes. Entretanto, cada um dos agentes envolvidos busca, de alguma maneira, defender também seus respectivos interesses e almeja suas ambições, do contrário não existe consenso, mas sim coação, dominação, controle ou termos correlatos que, no fim, significa a supressão da autonomia (CASTORIADIS, 1982) dos demais agentes envolvidos na relação social (BRITO, 2008, p. 21).

A liderança, conforme o autor, é legitimamente construída, sustentada por um processo de cooperação, excluindo a possibilidade de relações verticais, erigidas sob o princípio do comando/obediência. A cooperação concebida nos termos enunciados por Marx (apud Brito, 2008 , p. 21) como a "(...) forma de trabalho em que muitos trabalham juntos, de acordo com um plano, no mesmo processo de produção ou em processos de produção diferentes, mas conexos".

A discussão sobre o poder, todavia, pode ser pensada a partir de outra complexidade, renovadamente apregoada em distintos momentos por Haesbaert $(1997,2004,2009)$, destacando a multidimensionalidade do poder:

[...] podemos afirmar que o território, relacionalmente falando, ou seja, enquanto mediação espacial do poder, resulta da interação diferenciada entre as múltiplas dimensões desse poder, desde sua natureza mais estritamente política até 
seu caráter mais propriamente simbólico, passando pelas relações dentro do chamado poder econômico, indissociáveis da esfera jurídico-política (HAESBAERT, 2004, p. 93).

Com essa forma de conceber o poder, o autor não apenas amplia o olhar sobre o conceito, mas introduz uma discussão que tem encontrado fôlego e mobilizado crescentemente o interesse dos geógrafos, problematizando a dicotomia entre uma dimensão material autônoma em relação a uma dimensão imaterial-simbólica nas concepções de território.

\section{A multidimensionalidade do território}

Uma forte evidência da multidimensionalidade do conceito de território é a existência de trabalhos que tomam como centralidade dimensões distintas para pensar a territorialidade. Haesbaert (2004) empreendeu esforços sistemáticos na direção da explicitação da multidimensionalidade do território. O testemunho inequívoco pode ser observado no trabalho de categorização das abordagens do conceito de território no pensamento científico, identificando as grandes vertentes que estruturaram os estudos sobre esse conceito e suas derivações (territorialidade, des-re-territorialização).

Sumariamente, o autor identifica que o território vem sendo abordado em duas perspectivas principais: materialistas e idealistas. Os estudos desenvolvidos no âmbito de perspectiva materialista têm privilegiado a dimensão físico-concreta, compartimentada em três concepções. A naturalista, que considera o território com base nas relações entre sociedade e natureza, moldadas através do comportamento natural dos homens em relação ao seu meio físico. A jurídico-política, que concebe o território "como espaço delimitado e controlado através do qual se exerce um determinado poder, na maioria das vezes - mas não exclusivamente -, relacionado ao poder político do Estado" (HAESBAERT, 2004, p. 40). E a concepção econômica, segundo a qual o território é visto "como fonte de recursos e/ou incorporado no embate das classes sociais e na relação capital-trabalho, como produto da divisão 'territorial' do trabalho" (p. 40). A perspectiva idealista', imaterial, abstrata, "prioriza a dimensão simbólica e mais subjetiva, em que o território é visto, sobretudo, como produto da 
apropriação/valorização simbólica de um grupo em relação ao seu espaço vivido" (p. 40).

A multidimensionalidade, explícita, ou mesmo, implicitamente, é considerada por vários geógrafos. Embora, nos exercícios realizados para compreensão dos processos de territorialização, a literatura geográfica tenha conferido maior ênfase à dimensão material, focalizando, especialmente, uma ordem político-jurídica [como demonstrou Haesbaert (2004)], mais recentemente, abundam os estudos que passam a considerar de forma mais enfática o papel da dimensão imaterial, de caráter simbólico-cultural. Parte significativa do debate se assenta em uma distinção (às vezes, oposição) entre as dimensões material e imaterial, ou político-econômica e cultural-simbólica, e também na reafirmação do papel desempenhado pelos valores, pelas representações, pelo sentimento de pertencimento e pela identidade espacial no processo de construção da territorialidade.

Raffestin (1993 [1980]), em seu percurso teórico, pressupondo uma anterioridade do espaço em relação ao território, pois, o primeiro se torna o segundo pelo resultado da ação de atores sintagmáticos, admite que "ao se apropriar de um espaço, concreta ou abstratamente (por exemplo, pela representação), o ator 'territorializa' o espaço" (p. 143); afinal, "produzir uma representação do espaço já é uma apropriação, uma empresa, um controle, portanto, mesmo se isso permanece nos limites de um conhecimento" (p. 144).

Os termos controle, apropriação e domínio são frequentemente acionados nas concepções de território (como ocorre em Sack [1986], Raffestin [1993], Souza [1995], Haesbaert [1997, 2004], dentre outros). Partindo de uma distinção elaborada por Lefebvre, entre as noções de "dominação" e "apropriação", Haesbaert (1997) delas se apropria para reforçar a relevância da dimensão simbólico-cultural da territorialidade humana, uma vez que a dimensão material foi mais fortemente priorizada pela literatura geográfica. Atribuindo à dominação um caráter predominantemente funcional, distintamente da apropriação, cujo caráter seria prevalentemente simbólico, Haesbaert (1997) sugere que

(...) o território deve ser visto na perspectiva não apenas de um domínio ou controle politicamente estruturado, mas também de uma apropriação que incorpora uma dimensão 
simbólica, identitária e, porque não dizer, dependendo do grupo ou classe social a que estivermos nos referindo, afetiva (p. 41).

Nesses termos, o autor considera que o processo de territorialização conjuga processos de dominação e de apropriação, reunindo uma dimensão concreto-funcional e outra simbólico-afetiva. $\mathrm{Na}$ referência à dimensão simbólica, predominam as abordagens que a vinculam à ideia de identidade espacial, como aparece na definição de território de Knight, citado por Haesbaert (1997, p. 36), considerando o território como um "espaço ao qual está ligada uma identidade através de um grupo distinto que mantém ou ambiciona este território e que deseja obter total controle dele em proveito do grupo". Raffestin (1993), recuperando um entendimento de Soja, reconhece na territorialidade a existência de uma "identidade espacial", que pressupõe uma "compartimentação da interação humana no espaço" e lhe confere um "senso de exclusividade", pois, a "análise da territorialidade só é possível pela apreensão das relações reais recolocadas no seu contexto sóciohistórico e espaço-temporal” (p. 162).

Mesmo admitindo a multidimensionalidade, há geógrafos, no entanto, que advogam uma preponderância e uma anterioridade da dimensão simbólico-cultural em relação à política e à economia, conforme expresso abaixo.

O poder do laço territorial revela que o espaço está investido de valores não apenas materiais, mas também éticos, espirituais, simbólicos e afetivos. É assim que o território cultural precede o território político e com mais razão precede o espaço econômico (BONNEMAISON e CAMBRÈZY, 1996 apud HAESBAERT, 2004, p. 72).

Segundo Haesbaert (2004), o contexto de inspiração dos autores são as sociedades agrícolas pré-industriais e as sociedades de "caçadores e coletores" nas quais o território se erige, a partir de intensas relações afetivas com o espaço e do sentimento de pertencimento, princípios considerados produtores da identidade territorial.

Souza (2009), por outro lado, embora reconheça a presença das dimensões cultural e econômica para pensar o conceito de território, assume categoricamente 
a nuclearidade da dimensão política (por meio da noção de poder) como definidora.

O que 'define' o território é, em primeiríssimo lugar, o poder - e, nesse sentido, a dimensão política é aquela que, antes de qualquer outra, lhe define o perfil. Isso não quer dizer, porém, que a cultura (o simbolismo, as teias de significados, as identidades...) e mesmo a economia (o trabalho, os processos de produção e circulação de bens) não sejam relevantes ou não estejam 'contemplados' ao se lidar com o conceito (...) (p. 59-60).

Entretanto, não existe consenso no que se refere à compreensão da dimensão imaterial. Fernandes (2009) considera a multidimensionalidade ${ }^{14}$ como um princípio do conceito de território que ajuda a entender a ideia de totalidade, uma vez que esta se expressa pelas múltiplas dimensões do território e é composta por “(...) relações sociais, econômicas, políticas, ambientais, e culturais" (p. 202). O autor reafirma a multidimensionalidade, argumentando que "as disputas territoriais não se limitam á dimensão econômica" (p. 201), mas "ocorrem também no âmbito político, teórico e ideológico".

Ele sintetiza o caráter multidimensional de sua perspectiva admitindo a existência de territórios materiais e imateriais. No entanto, Fernandes (2009) restringe sua compreensão da dimensão imaterial ao "processo de construção do conhecimento e suas interpretações" (p. 210), uma vez que "o território imaterial pertence ao mundo das ideias, das intencionalidades, que coordena e organiza o mundo das coisas e dos objetos: o mundo material", pois, ele "(...) é formado por ideias e pensamentos diversos: conceitos, teorias, métodos, ideologias, paradigmas etc., que definem a leitura, o foco, a interpretação, a compreensão e, portanto, a explicação do objeto, tema ou questão" (p. 211). Concordamos que a esfera do conhecimento (científico) não está dissociada ou fora da realidade social como se fora um plano autônomo e deslocado dela, e, que seu processo de produção reflete sua complexidade histórica, por um lado, e é um

14 Além da multimensionalidade, o autor considera também a soberania, a totalidade, a pluriescalaridade, a intencionalidade e a conflitualidade como princípios do território (FERNANDES, 2009). 
componente fundamental da construção dos sentidos que afetam a dinâmica social, por outro lado. Todavia, em uma perspectiva mais ampla, a dimensão imaterial envolve os sistemas de valores e de representações (inclusive aquelas construídas pelo conhecimento científico) que compõem os processos de significação social, diretamente imbricadas e remetidas à realidade concreta.

Algumas concepções e estudos, ao priorizarem uma dimensão, acabam por secundarizar a outra, mas, têm ganhado evidência as perspectivas que trabalham com a ideia de imbricação e interdependência, nas quais as dimensões se interpenetram de modo mais complexo. Um exemplo desse tipo de entendimento observa-se abaixo.

O território envolve sempre, ao mesmo tempo, mas em
diferentes graus de correspondência e intensidade, uma
dimensão simbólico-cultural, através de uma identidade
territorial atribuída pelos grupos sociais como forma de
'controle simbólico' sobre o espaço onde vivem (sendo,
portanto, uma forma de apropriação) e uma dimensão mais
concreta, de caráter político disciplinar: o domínio do espaço
pela definição de limites ou fronteiras visando à
disciplinarização dos indivíduos e o uso/controle dos recursos
aí presentes (HAESBAERT, 1997, p. 42 ).

Essa perspectiva, que reconhece a inseparabilidade das dimensões material-imaterial, defendendo sua imbricação, pode ser constatada na conclusão de Di Méo (1998), refletindo sobre a construção do(s) território(s):

Sua edificação combina as dimensões concretas, materiais, aquelas dos objetos e dos espaços, aquelas das práticas e das experiências sociais, mas também as dimensões ideais das representações (ideias, imagens, símbolos) e dos poderes. Acrescentamos que esses diferentes registros encontram seu princípio unificador e sua coerência no sentido que os indivíduos conferem a sua existência terrestre, através do 
espaço que eles se apropriam e do qual eles fazem um valor existencial central (p. 273) ${ }^{15}$.

A reafirmação da multidimensionalidade, presente em Souza (2009), demonstra a complexidade do olhar sobre o processo de territorialização, situando o debate no âmbito teórico-metodológico; afinal, não se pode perder de vista que o estabelecimento de dimensões para compreensão da realidade é uma operação que se realiza no plano da análise, informadas pelas problemáticas efetivas sobre as quais nos debruçamos e delimitamos nosso foco.

Em meio a relações sociais complexas, uma dimensão pode aparecer, histórico-culturalmente, como a mais importante, o que não significa que ela seja a única relevante. Em cada caso concreto, ao se examinarem os fatores por trás de processos de territorializaçao, descobriremos, recuando no tempo e escavando o suficiente, um emaranhado de razões e motivações. A defesa de uma identidade pode estar associada a uma disputa por recursos e riquezas, no presente ou no passado; a cobiça material não é, de sua parte, descolável do simbolismo, da cultura (SOUZA, 2009, p. 60).

Os argumentos que conclamam a multidimensionalidade nos convocam a pensar na complexidade dos contextos geográficos e históricos que envolvem e conferem particularidade às problemáticas demarcadas. Haesbaert (2009) propõe compreender o processo territorialização a partir de um continuum de articulação territorial que admite a imbricação das múltiplas dimensões e se contrapõe à existência de territórios exclusivamente funcionais/materiais ou culturais/simbólicos.

Tomamos como referência nesse debate a ideia de um continuum de articulação territorial desde os territórios - ou

15 "Son édification combine les dimensions concrètes, matérielles, celles des objets et des espaces, celles pratiques et des expériences sociales, mais aussi les dimensions idéelles des représentations (idées, images, symboles) et des pouvoirs. Ajoutons que ces différents registres trouvent leur prinipe unificateur et leur cohérence dans le sens que les individus conferent à leur existence terrestre, au travers de l'espace qu'ils s'approprient et dont une valeur existentielle centrale" (DI MÉO,1998, p. 273). 
para sermos mais precisos, os processos de territorialização com maior carga funcional (e 'material', poderíamos acrescentar) até aqueles com maior carga simbólica, sem perder nosso foco nas relações de poder. Considerando os dois extremos (que, se existissem seria apenas como 'tipos ideais'), diríamos que não é possível conceber territórios puramente funcionais (já que sempre, por menos expressiva que seja, estará neles contida uma dimensão simbólica) nem territórios puramente simbólicos (neste caso, alguma referência a um espaço material, por alguns, denominado espaço - ou território - 'de referência identitária', deverá estar presente) (p. 106).

Saquet (2007) também enfatiza a multidimensionalidade como um componente fundamental para compreensão da produção territorial:

O processo de apropriação e produção territorial pode ser compreendido reconhecendo-se a relação espaço-tempo, o domínio ou o controle político, a apropriação simbólicoidentitária e afetiva e, concomitantemente, a dinâmica econômica, em unidade, no processo de reprodução da dominação social, em que o Estado e os agentes do capital se fundem histórica e incessantemente. (p. 130).

Para Saquet (2007), a territorialidade deve ser concebida como um "[...] movimento processual e relacional, de apropriação, dominação e produção (i)material (material-imaterial) do território (p. 158). O autor propõe uma abordagem territorial (i)material, buscando "identificar e caracterizar componentes e processos que fazem parte da (i)materialidade das formas e relações sociais [...]" (p. 131), considerando simultaneamente "o tempo, o espaço e o território, e aspectos da economia, da política e da cultura ([i]materialidade)" (p. 127), para construção de uma abordagem geográfica do território e do desenvolvimento econômico.

O conteúdo dessa discussão permite-nos realizar uma leitura do movimento do pensamento geográfico nas últimas três décadas, especialmente sobre o produto do acúmulo de parte relevante das reflexões que se debruçaram sobre a tarefa de teorizar o território, ampliando os horizontes conceituais para o reconhecimento e a compreensão de uma determinada forma de manifestação do comportamento espacial da 
sociedade. Destacam-se alguns aspectos que apontam características fundamentais para compreensão da territorialidade humana, como a multiescalaridade e a multidimensionalidade (inclusive das relações de poder que conformam os territórios).

\section{Considerações finais}

Nas últimas três décadas, observam-se a ampliação do debate teórico e a multiplicação das formulações do conceito de território na geografia, adquirindo um caráter cada vez mais operacional, em virtude de seu uso crescente nos estudos interpretativos da realidade. Um volume significativo e crescente de livros, artigos, teses, dissertações e monografias atestam esse movimento.

No entanto, instalou-se uma contenda acerca do risco de extensão do significado e uso do conceito, sob pena de perda de operacionalidade na tarefa de enfrentamento da compreensão da realidade. Essa discussão se colocou com o questionamento das amarras espaciais e temporais a que esteve submetido na Geografia Política Clássica e nos estudos da Ciência Política, cujo uso predominante esteve vinculado à existência do Estado nacional.

Os resultados desse processo apontaram para a construção de possibilidades de compreensão de fenômenos espaciais com manifestação nas escalas geográficas e históricas mais diversas. As territorialidades passaram a ser identificadas em perspectivas outras, não apenas remetidas à materialidade da política, mas vinculadas (e/ou incorporando) à dimensão simbólica do real. $\mathrm{O}$ fenômeno territorial também começa a ser reconhecido como produto das relações sociais de poder que se manifestam nas ações dos mais variados agentes sociais e, não apenas, como produto da ação estatal. $O$ foco dessas discussões pode ser anunciado nas três assertivas resumidamente apresentadas a seguir:

- Questionamento da concepção de território, concebido, exclusivamente, a partir de limites espaciais e temporais bem definidos e imutáveis, reduzido às fronteiras do Estado nacional e às longas durabilidades geradoras de identidade espacial. 
- Reforço do caráter político do espaço através do conteúdo do território, como produto/produtor da relação espaço-poder, considerando que as diferentes matrizes interpretativas sobre o poder permitem distintos aportes para pensar a territorialidade humana.

Problematização das concepções polarizadoras, unidimensionais e excludentes sobre o território, apontando para a superação da dicotomia material-simbólico e para perspectivas que contemplem a ideia de multidimensionalidade.

\section{COMPONENTES DEFINIDORES DO CONCEITO DE TERRITÓRIO:}

\section{A MULTIESCALARIDADE, A MULTIDIMENSIONALIDADE E A RELAÇÃO ESPAÇO-PODER}

Resumo: A multiescalaridade e multidimensionalidade da concepção de território e a centralidade da relação espaço-poder para pensar a territorialidade humana têm ocupado posição privilegiada no debate geográfico nas últimas três décadas, indicando os componentes fundamentais da redefinição desta categoria neste campo disciplinar. É no rastreamento, aclaramento e organização dessas discussões que se encontra estruturado este texto.

Palavras-chave: território, poder, multiescalaridade, multidimensionalidade

\section{DEFINING COMPONENTS OF THE CONCEPT OF TERRITORY: MULTI-ESCALARITY, MULTIDIMENSIONALITY AND RELATIONSHIP SPACE-POWER}

Abstract: Multi-scalarity and multidimensionality in the conceptualization of territory and the centrality on the relationship between space and power to think about human territoriality have occupied a privileged position in geographical debate through the last three decades. They indicate key elements for redefinition of this category in Geography. This text is based on the screening, clarification and organization of this discussion.

Keywords: territory, power, multi-scalarity, multidimensionality 


\section{BIBLIOGRAFIA}

ARENDT, H. (2009). Sobre a Violência. Rio de Janeiro: Civilização Brasileira. BOBBIO, N. (2007). Estado, Governo, Sociedade: Para uma teoria geral da política. 13. ed. São Paulo: Paz e Terra.

BRITO, C. (2005). Algumas observações sobre o conceito de território. Agora, Santa Cruz do Sul, v. 11, n. 2, jul./dez. p. 115-131.

baiano. Salvador: EDUFBA.

(2008). A PETROBRAS e a gestão do território no Recôncavo

COSTA, W. M. (1992). Geografia Política e Geopolítica: Discursos sobre o Território e o Poder. São Paulo: Hucitec/Edusp.

DI MÉO, G. (1998). Géographie Sociale et Territoires. Paris: Nathan.

DUARTE, A. (2009). Poder e violência no pensamento político de Hannah Arendt : uma reconsideração. In: ARENDT, H. Sobre a Violência. Rio de Janeiro: Civilização Brasileira.

FERNANDES, B. M. (2009). Sobre a tipologia de territórios. In: SAQUET, M. A.; SPOSITO, E. S. Território e territorialidades: teorias, processos e conflitos. São Paulo: Expressão Popular.

FOUCAUlT, M. (2002). Em Defesa da Sociedade. São Paulo: Martins Fontes. . (2007). Microfísica do poder. 23. ed. Rio de Janeiro: Graal.

de Janeiro: Graal.

(2009a). História da Sexualidade I. A Vontade de Saber. 19. ed. Rio . ( 2009b). Vigiar e Punir. 36. ed. Rio de Janeiro: Vozes.

HAESBAERT, R. (1997). Des-territorialização e identidade: a rede gaúcha no Nordeste. Niterói: EdUFF.

. (2004). O Mito da Desterritorialização. Rio de Janeiro: Bertrand Brasil.

(2009). Dilemas de conceitos: espaço-território e contenção territorial. In: SAQUET, M. A.; SPOSITO, E. S. Território e territorialidades: teorias, processos e conflitos. São Paulo: Expressão Popular.

HOBBES, T. (2005). Leviatã, ou matéria, forma e poder de um Estado eclesiástico e civil. São Paulo: Rideel.

MORAES, A. C. R. (1990). Ratzel: Geografia. São Paulo: Ática. 
PERISSINOTTO, R. M. (2008). Poder: imposição ou consenso ilusório? In: NOBRE, R. R. O poder no pensamento social: dissonâncias. Belo Horizonte: Editora UFMG.

RAFFESTIN, C. (1986). Ecogénèse territoriale et territorialité. In: AURIAC, F.; BRUNET, R. (coord.). Espaces, jeux et enjeux. Paris: Fayard-Diderot.

. (1988). Repères pour une théorie de la territorialité humaine. In: DUPUY, G. et al. Réseaux territoriaux. Caen, Paradigma.

. (1993 [1980]). Por uma Geografia do Poder. São Paulo: Ática.

RONCAYOLO, M. (1986). Território. In: ENCICLOPEDIA EINAUDI. V. 8. Região. Porto: Imprensa Nacional Casa Moeda, p. 262-290.

RUSSELL, B. (1979 [1938]). O poder: uma nova análise social. Rio de Janeiro: Zahar Editores.

SACK, R. D. (1986). Human territoriality: its theory and history. London: Cambridge University.

SAQUET, M. A. (2007). Abordagens e concepções de território. São Paulo: Expressão Popular.

SOUZA, M. J. L. (1995). O Território: sobre espaço de poder, autonomia e desenvolvimento. In: CASTRO. I. E. de et al. (orgs.) Geografia: Conceitos e Temas. Rio de Janeiro: Bertrand Brasil.

(2009). "Território" da divergência (e da confusão): em torno das imprecisas de um conceito fundamental. In: SAQUET, M. A.; SPOSITO, E. S. Território e territorialidades: teorias, processos e conflitos. São Paulo: Expressão Popular.

WEBER, M. (1994). Economia e Sociedade: fundamentos de sociologia compreensiva. 3. ed. Brasília: EdUNB.

Data de Submissão: 27/04/2012

Data de Aprovação: 22/03/2013 